http://dx.doi.org/10.1590/0370-44672020730012

Allan Erlikhman Medeiros Santos ${ }^{1,3}$
https://orcid.org/0000-0003-4302-3897
Talita Káren Magalhães Amaral1,4
https://orcid.org/0000-0002-6859-1762
Guilherme Alzamora Mendonça ${ }^{1,5}$
https://orcid.org/0000-0002-4516-9403
Denise de Fátima Santos da Silva ${ }^{2,6}$
https://orcid.org/0000-0002-9695-2449
${ }^{1}$ Centro Federal de Educação Tecnológica de Minas
Gerais - CEFET-MG, Araxá - Minas Gerais - Brasil.
${ }^{2}$ Universidade Federal de Minas Gerais - UFMG,
Instituto de Geociências - IGC/CPMTC,
Belo Horizonte - Minas Gerais - Brasil.
E-mails: ${ }^{3}$ allanerlikhman@cefetmg.br,
${ }^{4} \underline{\text { talitamagalhaees@gmail.com, }}$
${ }^{5}$ guilherme.alzamora@gmail.com,
${ }^{6}$ denisefssilva61@gmail.com

\section{Open stope stability assessment through artificial intelligence}

\begin{abstract}
Underground mining is a set of methods that allows the extraction of ore in depth, ensuring sustainability and economic viability. One of the problems that arise in underground mine operations is open stope stability. The method for assessing stability of open stopes is the stability graph proposed by Mathews et al. (1981). It is possible to estimate and provide information about this stability and assist in the decision making about its viability. With the data obtained from 35 open stopes from a Zinc mine, the present study aims to use artificial intelligence techniques, specifically artificial neural networks, to process the data and classify the open stopes according to the stability regions of the graph. As a result, the applied methodology presented good assertiveness for the classification of two classes, stable and unstable open stopes, resulting in a global probability success of $82 \%$ overall hit probability and $18 \%$ apparent error rate. For the classification into three classes, adding the transitional open stopes, the internal validation presented a global probability success of $91 \%$ and apparent error rate of $9 \%$. In external validation, the network evaluation measures presented values of global probability success of $42 \%$ and apparent error rate of $58 \%$.
\end{abstract}

Keywords: open stope stability, artificial neural networks, artificial intelligence, sublevel stoping. age, loss of life and dilution of reserves. In this study, the underground mining method applied is Vertical Retreat Mining, which is a form of the sub-level mining method. In this scenario, the ore grade decreases as the depth of the mine increases. Another relevant aspect that must be observed is the presence of ore lenses around the excavations. Due to the small thickness of these lenses, they end up influencing the stability of the excavation, generating areas of weakness where cuttlefish fall. This instability can lead to an increase in the operational dilution, which is a worrying factor in view of the increase in the cost of transportation, in the problems caused in the beneficiation stage, and consequently, in the project's revenue.

The methodology currently used is the stability graph proposed by Mathews et al. (1981) for mines $1000 \mathrm{~m}$ deep in Canada. However, the results obtained with this methodology have not responded well to the field observations of the mine and, in addition, because it is a methodology empirically proposed, the tendency is that it adapts better to the region where it was proposed. According to Oliveria (2012), it is a constant challenge to estimate this stability in view of anisotropy, heterogeneity, and masses. In relation to the stability graph there are contributions made by Potvin (1988), Palkanis (1986) and Mawdesley the presence of discontinuities in rock proposed by Mathews et al. (1981), 
et al. (2001).

In view of these problems, the objective of this study is to propose an alternative methodology to assess the stability of an open stope of an underground mine using artificial intelligence, more specifically, the technique of Artificial Neural Networks (ANNs). This technique capable of receiving an unlimited amount of data and learn its characteristics in order to be able to classify it with the lowest possible error value.

\section{Materials and methods}

The original database consists of two variables: number of stability and hydraulic radius, in addition to the stability status, constituting a total of 35 open stopes. Two situations were studied: the classification in two classes, stable and unstable, and the classification into three
ANN is a computer system structured to receive information, interpret it and make decisions based on training (Nola, 2015). This technique works in a way similar to a neuron, where the system has the ability to "learn" through exposure to a set of input samples combined with the action that would be appropriate for each input (Ferentinou and Fakir, 2017). The application of these techniques has been widely used in rock mechanics and in particular in the prediction of rock properties, such as in the works of Kahraman et al. (2010); Rafiai and Jafari (2011); Kumas et al. (2011);and Manouchehrian (2012). In addition, other authors were able to predict other geotechnical properties through ANNs, such as in the study by Yang and Rosenbaum (2002), who investigated the availability of estimating the geotechnical properties of a sandstone based on the geological indicators and the study by Celeste and Oliveira (2019), who estimated the resilience module of asphalt pavements. classes: stable, unstable and transition.

According to Figure 1, the original database was randomly divided into two samples, the training sample for network training and the test sample for network validation, both corresponding to $50 \%$ of the original database. Forty networks were trained for each situation; that is, constituting 40 training and test samples selected at random. The network feed was positive, feedforward, and the learning algorithms used were backpropagation (for two classes) and the resilient backpropagation (for three classes).

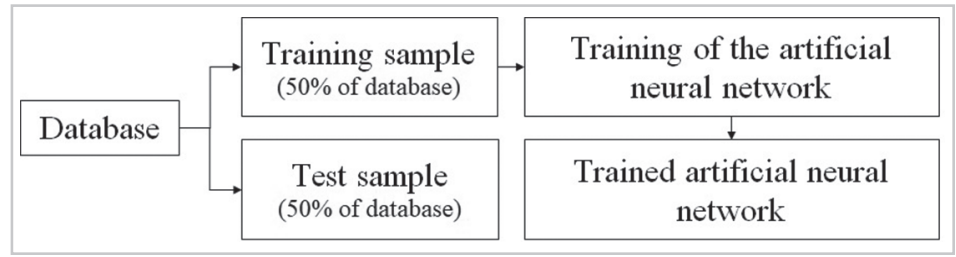

Figure 1 - Flowchart of the applied methodology.ons used in this methodology.

In this study, two forms of validation will be discussed: the internal validation that uses the trained network to predict the classes in the training sample; and external validation that uses the trained network to predict the classes in the test sample. Figure 2 shows the flowchart of validations used in this methodology.

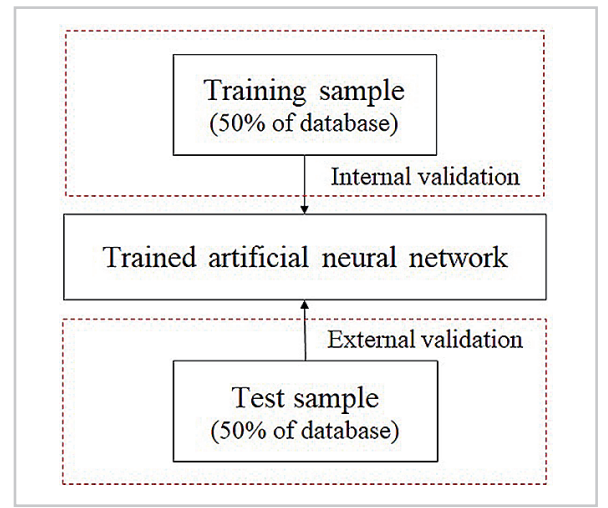

Figure 2 - Flowchart of the validation methodology.

The results of the artificial neural network can be evidenced by confusion matrices shown by Table 1 and Table 2, for the two types of classification studied.

Table 1 - Confusion matrix for the situation with two stability classes.

\begin{tabular}{c|c|c|c|c}
\hline Confusion matrix 2 classes & \multicolumn{4}{|c}{ Prediction } \\
\hline \multirow{3}{*}{ True } & Stable & Unstable & Total & \\
\cline { 2 - 5 } & Stable & $n_{11}$ & $\mathrm{n}_{10}$ & $\mathrm{n}_{11}+\mathrm{n}_{10}$ \\
\cline { 2 - 5 } & Unstable & $n_{01}$ & $\mathrm{n}_{00}$ & $\mathrm{n}_{01}+\mathrm{n}_{00}$ \\
\cline { 2 - 5 } & Total & $\mathrm{n}_{11}+\mathrm{n}_{01}$ & $\mathrm{n}_{10}+\mathrm{n}_{00}$ & $\mathrm{n}_{\text {total }}$ \\
\hline
\end{tabular}


Table 2 - Confusion matrix for the situation with three stability classes.

\begin{tabular}{c|c|c|c|c|c}
\hline Confusion matrix 3 & & Prediction & Unstable & Transition & Total \\
\hline classes & & Stable & $\mathrm{n}_{10}$ & $\mathrm{n}_{12}$ & $\mathrm{n}_{11}+\mathrm{n}_{10}+\mathrm{n}_{12}$ \\
\hline True & Stable & $\mathrm{n}_{11}$ & $\mathrm{n}_{00}$ & $\mathrm{n}_{02}$ & $\mathrm{n}_{01}+\mathrm{n}_{00}+\mathrm{n}_{02}$ \\
\hline & Unstable & $\mathrm{n}_{01}$ & $\mathrm{n}_{20}$ & $\mathrm{n}_{22}$ & $\mathrm{n}_{21}+\mathrm{n}_{20}+\mathrm{n}_{22}$ \\
\hline & Transition & $\mathrm{n}_{21}$ & $\mathrm{n}_{10}+\mathrm{n}_{00}+\mathrm{n}_{20}$ & $\mathrm{n}_{02}+\mathrm{n}_{22}$ & $\mathrm{n}_{\text {total }}$ \\
\hline & Total & $\mathrm{n}_{11}+\mathrm{n}_{01}+\mathrm{n}_{21}$ & & \\
\hline
\end{tabular}

The values $\mathrm{n}_{11}, \mathrm{n}_{00}$ and $\mathrm{n}_{22}$ are the number of correct predicted in the classification of stable, unstable and transition open stopes, respectively. The values n10 and $n_{12}$ represent the number of stable open stopes that the network has classified as unstable, or transition. The values $\mathrm{n}_{01}$ and $\mathrm{n}_{02}$ show the number of unstable open stopes classified as stable and in transition. The value $n_{21}$ and $n_{20}$ is the number of transition open stopes classified as stable and unstable, respectively.

The evaluation measures of the trained artificial networks were the global prob- ability of success (GPS) and the apparent error rate (AER). From Equations 1 and 2, we have the calculation of $\mathrm{GPS}_{2 \text { classes }}$ and $\mathrm{AER}_{2 \text { classes }}$, respectively for classification into two classes. In Equations 3 and 4, GPS 3 classes and $\mathrm{AER}_{3 \text { classes }}$ are calculated, respectively, for classification into three classes.

$$
\begin{gathered}
G P S_{2 \text { classes }}=\frac{n_{11}+n_{00}}{n_{10}+n_{11}+n_{01}+n_{00}} * 100 \\
A E R_{2 \text { classes }}=\frac{n_{10}+n_{01}}{n_{10}+n_{11}+n_{01}+n_{00}} * 100 \\
G P S_{3 \text { classes }}=\frac{n_{11}+n_{00}+n_{22}}{n_{10}+n_{11}+n_{01}+n_{00}+n_{22}+n_{20}+n_{21}+n_{12}+n_{02}} * 100 \\
A E R_{3 \text { classes }}=\frac{n_{21}+n_{12}+n_{02}+n_{01}}{n_{10}+n_{11}+n_{01}+n_{00}+n_{22}+n_{20}+n_{21}+n_{12}+n_{02}} * 100
\end{gathered}
$$

In the classification into two stability classes: stable open stopes and unstable open stopes, the database had a total of 23 highlights. The package used was the neuralnet package, proposed by Fritsch and Günther (2010). The network configuration is in accordance with Haykin (1999). Two neurons were used in the middle layer, with a hyperbolic tangent activation function. Figure 3 illustrates the structure of the network used.

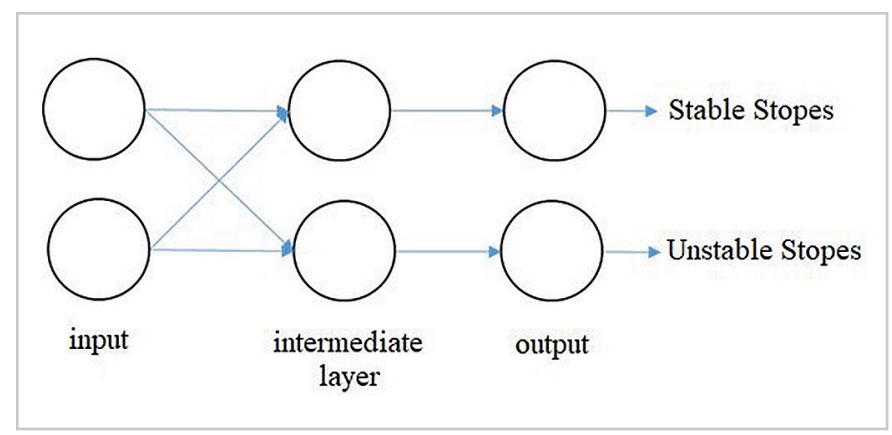

Figure 3 - Structure of the artificial neural network used for classification into two stability classes.

The network errors in this situation were calculated and classified as type 1 and type 2, considering only the network errors as a universe. These errors were identified as error 1 where the unstable open stopes are classified as

$$
\begin{aligned}
& \text { Error } 1=\frac{n_{01}}{n_{10}+n_{01}} * 100 \\
& \text { Error } 2=\frac{n_{10}}{n_{10}+n_{01}} * 100
\end{aligned}
$$

stable (Equation 5); and error 2 where stable open stopes are classified as unstable (Equation 6).
In the case of three stability classes: stable open stope, transition open stope and unstable open stope, the database had a total of 35 open stopes. The package used was the neuralnet package, proposed by Fritsch and Günther (2010). In this problem, two intermediate layers were used with four neurons in each layer, with a hyperbolic tangent activation function. The network learning algorithm was the resilient backpropagation. Figure 4 illustrates the structure of the network used. 


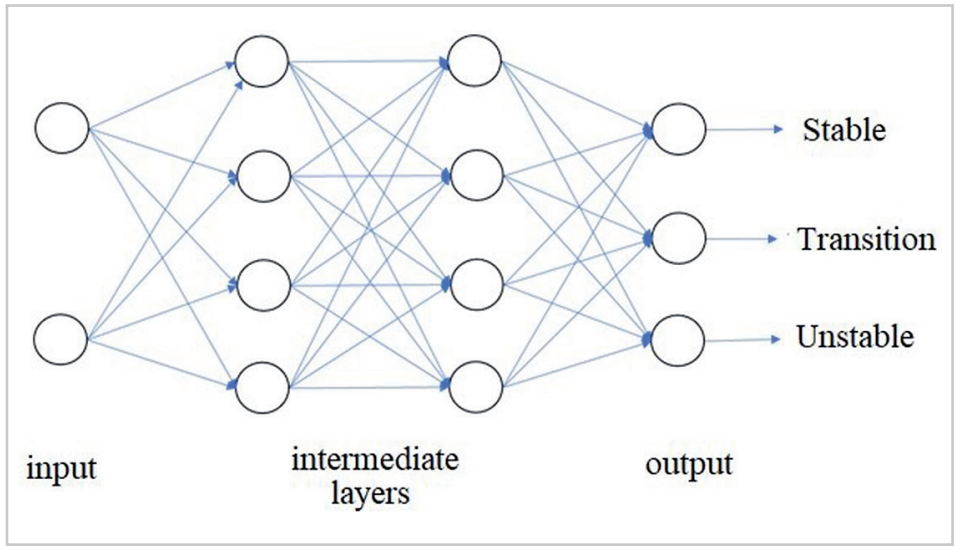

Figure 4 - Structure of the neural network used for classification into three stability classes.

\section{Results and discussions}

Figure 5 shows the scatterplot graphs for the hydraulic radius of variables and stability number for the open stopes in the two classification situations under study, being the condition for two classes and the condition for three classes. It is observed that the distribution of the open stopes in transition makes it difficult to separate into areas, such as in the stability graphs of Mathews et al. (1981) and Potvin (1988).

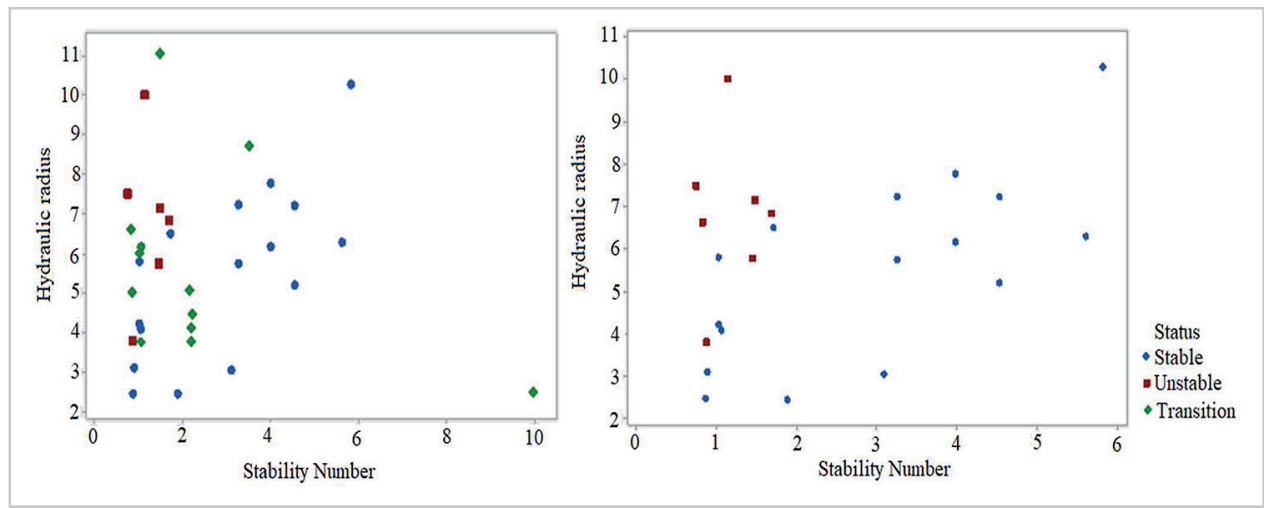

Figure 5 - Dispersion graphs for three-class and two-class stability.

First, for the classification problem in two classes: stable open stope and unstable open stope, Figures 6 and 7 show the be- havior of the GPS ${ }_{2 \text { classes }}$ and $\mathrm{AER}_{2 \text { classes }}$ of the network trained in internal and external validation for the 40 iterations performed, respectively. In Figures 6 and 7, notice that in the internal validation, the network presents a stable result, without representative peaks.

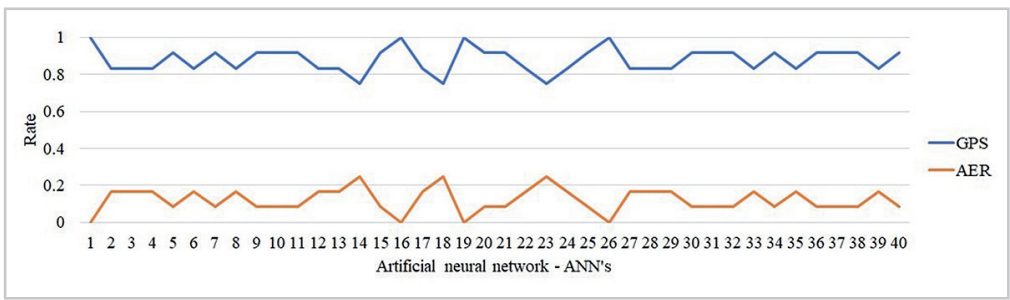

Figure 6 - Result of the internal validation for two stability classes.

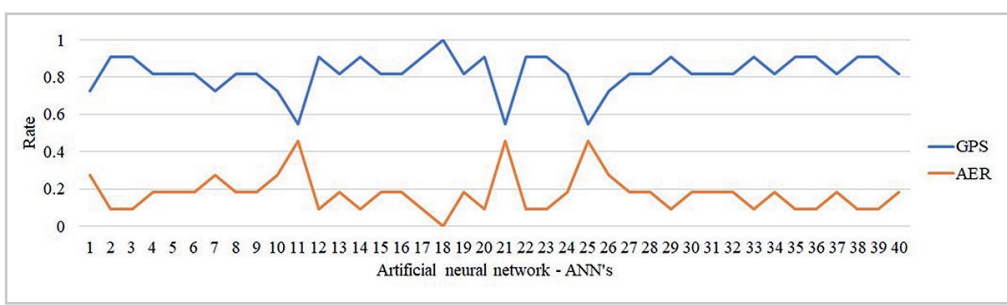

Figure 7 - Result of external validation for two stability classes.

In external validation, it is possible to observe three peaks of increase in $\mathrm{AER}_{2 \text { classes }}$, but if compared to the number of iterations performed, these isolated peaks do not compromise the stability of the network. In addition, it is possible to observe points where the network correctly classifies all highlights. Table 3 shows the statistical summary of the results of the network. 
Table 3 - Statistical summary of the classification results for two stability classes.

\begin{tabular}{c|c|c|c|c}
\hline Validation & Variablel & Average & Minimum & Maximum \\
\hline Internal & $\mathrm{GPS}_{2 \text { classes }}$ & 0.88 & 0.75 & 1.00 \\
\hline Internal & $\mathrm{AER}_{2 \text { classes }}$ & 0.12 & 0.00 & 0.25 \\
\hline External & $\mathrm{GPS}_{2 \text { classes }}$ & 0.83 & 0.55 & 1.00 \\
\hline External & $\mathrm{AER}_{2 \text { classes }}$ & 0.17 & 0.00 & 0.45 \\
\hline Internal & Error 1 & 0.61 & 0.00 & 1.00 \\
\hline Internal & Error 2 & 0.29 & 0.00 & 1.00 \\
\hline External & Error 1 & 0.43 & 0.00 & 1.00 \\
\hline External & Error 2 & 0.55 & 0.00 & 1.00 \\
\hline
\end{tabular}

In validations, the network presented an average GPS $_{2 \text { classes }}$ of $88 \%$ and $83 \%$, with a minimum value of $75 \%$. This is a remarkable result since the network presents high values of global probability of correctness in the great majority of the iterations it performs. In relation to $\mathrm{AER}_{2 \text { classes }}$, when stratifying the two types of errors that the network can make, Error 1 appears with greater recurrence, representing on average $61 \%$ of the total errors of each generated network, as shown in Table 3. Error 2 represents on average $29 \%$ of the total errors of each generated network. This can interpret as a non-conservative trend in the network, since Error 1, whose unstable open stopes were classified as stable, occurred more frequently. Figure 8 shows what one of the networks obtained for this classification condition.

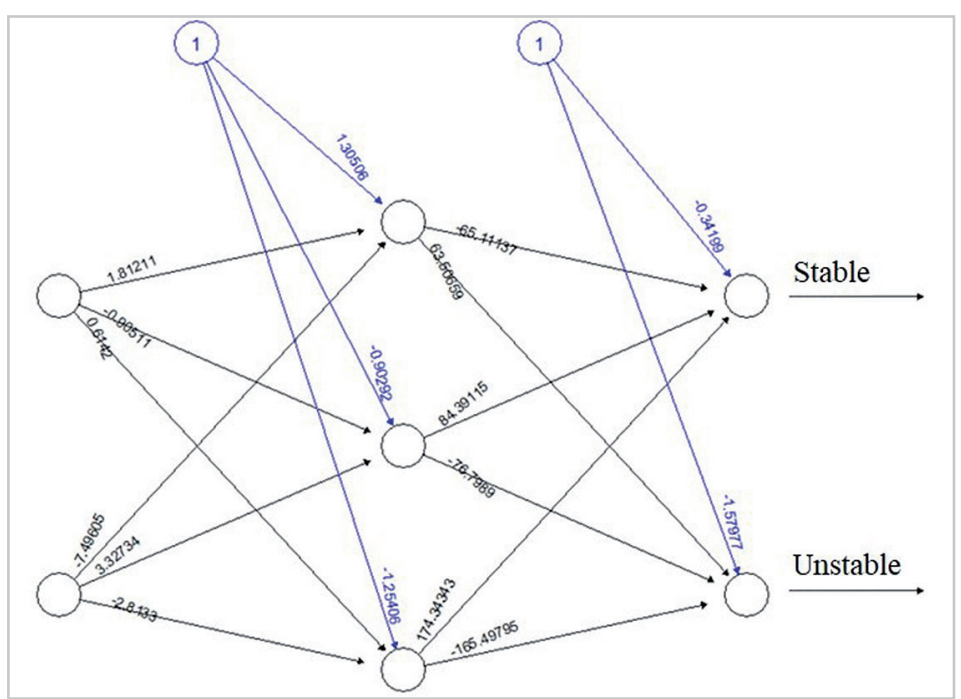

Figure 8 - Result of the artificial neural network, in the classification in two classes.

Regarding the results for the classification problem into three classes: stable, unstable and transition enhance- ments, Figures 9 and 10 show the results obtained regarding GPS classes $_{3}$ and $\mathrm{AER}_{3 \text { classes }}$, in the internal and external validations, respectively. Table 4 shows the statistical summary for the neural network assessment measures.

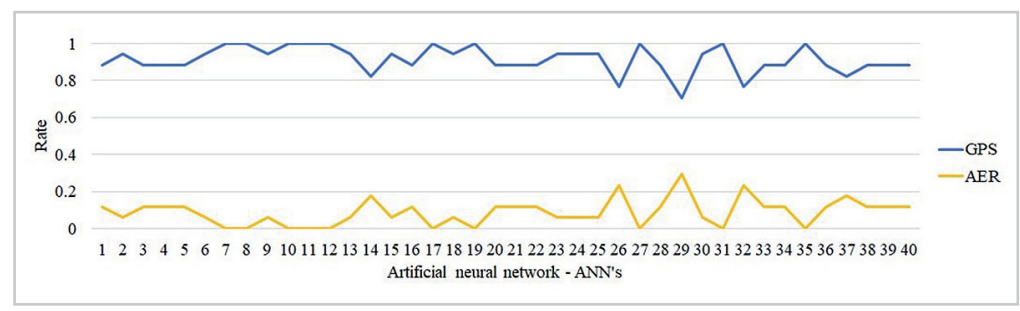

Figure 9 - Result of internal validation for three stability classes.

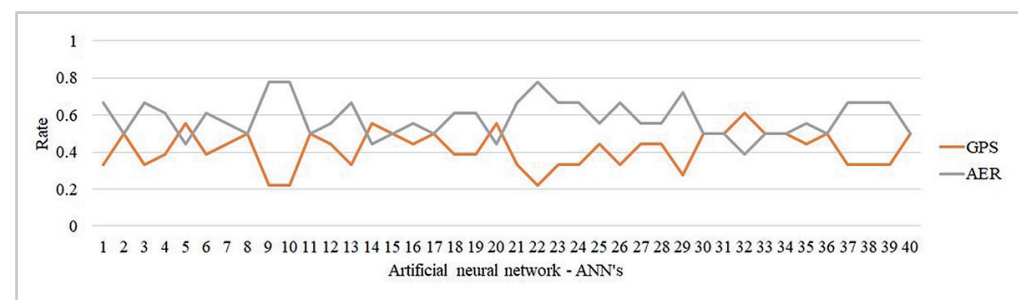

Figure 10 - Result of internal validation for three stability classes. 
Table 4 - Statistical summary of the classification results for three stability classes.

\begin{tabular}{c|c|c|c|c}
\hline Validation & Variable & Average & Minimum & Maximum \\
\hline Internal & $\mathrm{GPS}_{3 \text { classes }}$ & 0.91 & 0.71 & 1.00 \\
\hline Internal & $\mathrm{AER}_{3 \text { classes }}$ & 0.09 & 0.00 & 0.29 \\
\hline External & $\mathrm{GPS}_{3 \text { classes }}$ & 0.42 & 0.22 & 0.61 \\
\hline External & $\mathrm{AER}_{3 \text { classes }}$ & 0.58 & 0.39 & 0.77 \\
\hline
\end{tabular}

In the internal validation the $\mathrm{GPS}_{3 \text { classes }}$ was, on average, equal to $91 \%$, with maximum values of $100 \%$ in some iterations, and the $\mathrm{AER}_{3 \text { classes }}$ equal to $9 \%$ on average, and these are very relevant results due to the complex- ity of the problem. Regarding external validation, the results oscillated in average values of $42 \%$ and $58 \%$, for GPS3 $3_{\text {classes }}$ and AER $_{3 \text { classes }}$, which are considered low values. The low number of enhancement data and the complex- ity of the classification in three overlying classes culminated in these results. Figure 11 shows one of the networks obtained for the condition of classification into three classes: stable, unstable and transition highlights.

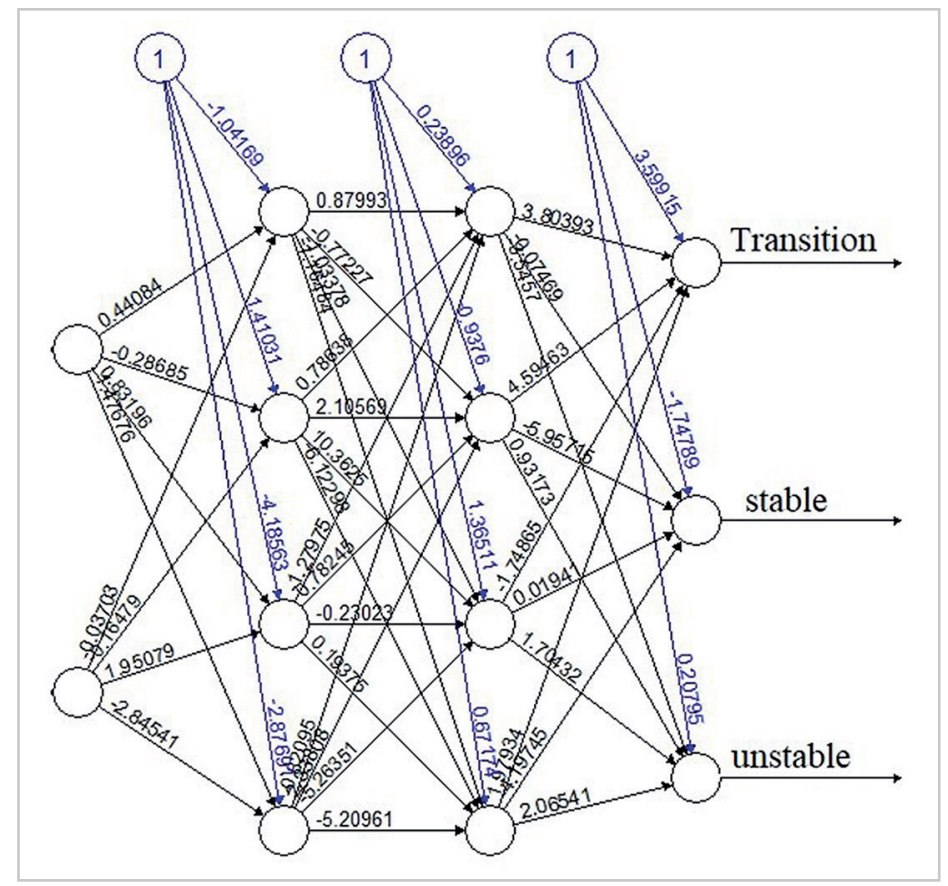

Figure 11 - Result of the artificial neural network, in the classification in three classes.

\section{Conclusions}

The proposed methodology proved to be capable of being used to assess the open stope stability. The networks were able to identify patterns and satisfactorily classify the studied open stopes. Two situations were presented: two stability classes and three stability classes. The results for the first situation proved to be more effective.
In the first situation addressed, for internal validation, on average the $\mathrm{GPS}_{2 \text { classes }}$ was $88 \%$ and $\mathrm{AER}_{2 \text { classes }}$ was $12 \%$ and for external validation, on average the rates were $83 \%$ and $17 \%$. In the classification for three classes, the most complex situation studied in herein, the results for internal validation were $91 \%$ for $\mathrm{GPS}_{3 \text { classes }}$ and $9 \%$ for $\mathrm{AER}_{3 \text { classes }}$. However, for external validation the results were not satisfactory, with the GPS 3 classes found equal to $42 \%$ and the $\mathrm{AER}_{3 \text { classes }}$ equal to $58 \%$ and this may be due to the small number of data available for the study.

This research is innovative and the results obtained can be an alternative methodology to the Stability Graph, mainly considering the results of the situation for two classes.

\section{Acknowledgements}

The authors would like to thank Brazilian Research Council (CNPq) for supporting this research.

\section{References}

CELESTE, A. B.; OLIVEIRA, F. H. L. Study of retroanalysis of asphaltic pavements resilience modules with the use of artificial neural networks. Transportes, v. 27, n. 4, p.123-133, 2019.

FERENTINOU, M.; FAKIR, M. An ANN approach for the prediction of uniaxial compressive strength, of some 
sedimentary and igneous rocks in eastern KwaZulu-Natal. Procedia Engineering, v. 191, p.1117-1125, 2017.

FRITSCH, S.; GÜNTHER, F. Neuralnet: training of neural networks. The R Journal, v. 2, n. 1, p. 30-38, 2010.

HAYKIN, S. S. Neural networks: a comprehensive foundation. 2nd ed, Prentice Hall, 1999. 842p.

KAHRAMAN, S.; ALBER, M.; FENER, M.; GUNAYDIN, O. The usability of cerchar abrasivity index for the prediction of UCS and E of Misis fault breccia; Regression and artificial neural networks analysis. Expert Systems with Applications, v. 37, n. 12, p. 8750-8756, 2010.

KUMAR, B. R.; VARDHAN, H.; GOVINDARAJ, M. Prediction of uniaxial compressive strength, tensile strength and porosity of sedimentary rocks using sound level produced during rotary drilling. Rock Mechanics and Rock Engineering, v. 44, p. 613-620, 2011.

MANOUCHEHRIAN, A.; SHARIFZADEH, M.; MOGHADAM, R. H. Application of artificial neural networks and multivariate statistics to estimate UCS using textural characteristics. International Journal of Mining Science and Technology, v. 22, n. 2, p. 229-236, 2012.

MATHEWS, K. E.; HOEK, E.; WYLIE, D. C.; STEWART, S. B. V. Prediction of stable excavation spans for mining at depths below 1,000 $\mathrm{m}$ in hard rock mines. Ottawa: CANMET, 1981. (Canmet Report DSS Serial No. OSQ80-00081).

NOLA I. T. S. Avaliação de dados geológico-geotécnicos prévios para elaboração de carta de eventos perigosos de movimentos de massa gravitacionais por meio de redes neurais artificiais e probabilidade. 2015. 249 f. Dissertação (Mestrado em Geotecnia) - Escola de Engenharia de São Carlos, Universidade de São Paulo, São Carlos, 2015.

OLIVEIRA, M. M.; PINTO, C. L. L.; DUTRA, J. 1. G. Potvin stability graph applied to brazilian geomechanic environment. REM - Revista Escola de Minas, v. 67, n. 4, p. 413-419, 2014.

POTVIN, Y. 1988. Empirical open stope design in Canada. 1988. $350 \mathrm{f}$. Thesis (PhD) - The University of British Columbia, Vancouver, 1988.

RAFIAI, H.; JAFARI, A. Artificial neural networks as a basis for new generation of rock failure criteria. International Journal of Rock Mechanics and Mining Sciences, v. 48, n. 7, p.1153-1159, 2011.

YANG, Y.; ROSENBAUM, M. S. The artificial neural network as a tool for assessing geotechnical properties. Geotechnical \& Geological Engineering, v. 20, n. 2, p. 149-168, 2002.

Received: 5 February 2020 - Accepted: 29 March 2020. 